\title{
Concerning Ice
}

\section{High Pressure Experiments on Water Carried on by Dr. Bridgman of Harvard}

S UMMER is at hand, and anything cooling is of in$S$ terest. In this connection it may be asked how the reader would like to have a choice of five kinds of ice? The possibility of such a choice is not far away, ac cording to recent discoveries in experimental science. And together with the new facts about ice, other amazing discoveries have been made. Among them is the fact that steel can be stretched more than its own diameter before breaking; that ordinarily soft and under pressure; that water can be decreased in volume almost at will without removing any of the contents. The experiments on high pressure outlined, with others, are being conducted by Dr. P. W. Bridgman of the Jefferson Physical Laboratory at Harvard Univer sity. In these experiments pressures were carried up to ten times the firing pressure of smokeless powder in large guns. A pressure of 300,000 pounds to the square inch was obtained. To visualize this figure in another way, it represents the pressure that would be exerted by a body of water 120 miles deep. It would take a column of solid rock some fifty miles high to exert such a pressure on its base.

Under the infiuence of such pressure as this, substances ordinarily soft and pliable show remarkable stiffness. Paraffin wax at 300,000 pounds is more rigid than soft steel. A piece of the steel, bedded in the paraffin when the latter substance is made to fiow under this pressure, will go with the stream and become bent and distorted with the wax, now harder than itself. Soft India rubber, it was found, at these itself. Soft India rubber, it was found, at these
pressures becomes so brittle that it will crack like glass, and so hard that irregularities in its surface can be impressed upon soft steel.

The first subject chosen for the measurement of compressibility was water, and in this article attention will be centered on it Water is generally considered almost incompresible, but under a pressure of 180,000 pounds to the square inch the astonishing decrease in

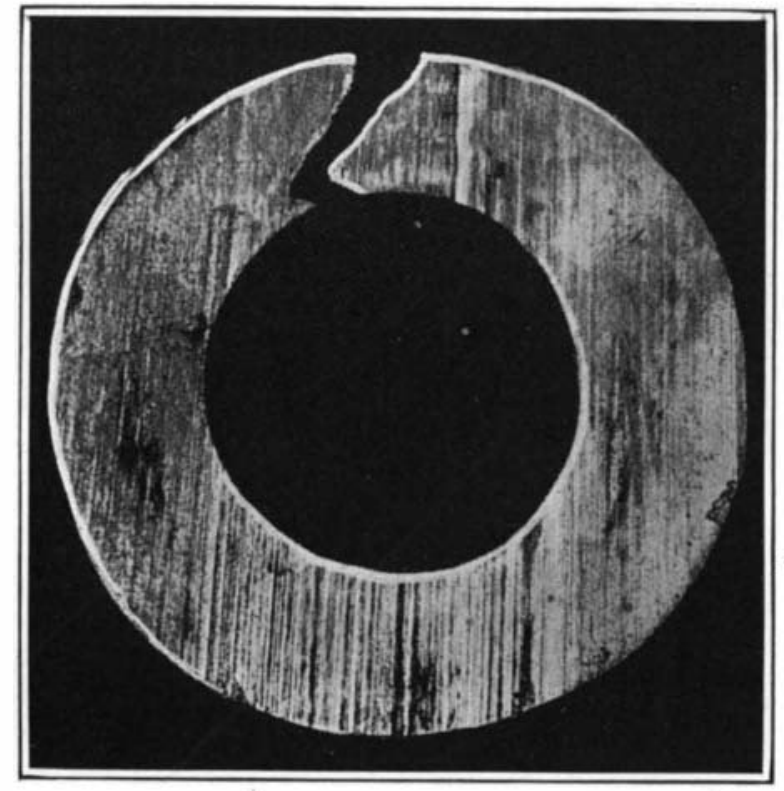

Cross-section of the cylinder shown in the upper left view of the group below

volume of 20 per cent is produced. This phenomenon occurs without the slightest decrease in the actual mass of water present. But certain irregularities in the water induced the experimenter to believe that he was measuring sometimes liquid water and sometimes ice.

Ice usually weighs less than water; that is why it floats. But under the pressures applied by Dr. Bridg. man there are four different kinds of ice which are heavier than water. Under ordinary circumstances, ume; but under these high pressures the freezing is accompanied by a decrease in volume with a correspond ing decrease in pressure, while when the ice melts again to water the volume increases and the pressure rises.

An interesting by-product of the experiments was the designing of a packing which would keep absolutely tight the ressel in which the pressures were to be produthe preventing the liquid from leaking out. There duced, preventing the liquid from leaking out. There was absolutely no diffculty in this regard after while, for it was discovered that with the right packing, the greater the pressure the less can the liquid leak.

The ordinary screw-tightened packing is certain to leak, because the pressure so exerted cannot possibly equal the pressure of the experiment which exists in the fluid. A packing so compressed will leak as soon as the pressure of the screw is exceeded by that of the water which the packing holds back. But with the simple idea of a packing that tightens itself by the pressure of the vessel, the only limit to the compression pressure of the vessel, the only limit to the compression that can be reached is set by the strength of the vessel
itself. The problem was faced with misgivings, for the itself. The problem was faced with misgivings, for the pressures it was proposed to exert were unheard of with ordinary vessels. The second part liminary work, therefore, consisted in finding what pre sures a steel vessel would selected as the best material of which to make the container. These experiments were not without danger, for in the event of the vessel's failure there would be an explosion that might be serious.

In all the experiment's the pressures were produced by pushing a piston, by means of a hydraulic press, into the cylinder containing the liquid. Two very interesting problems in rekative strength were introduced, for the two parts of the apparatus were subjected to different strain In the piston the strain is one of compression, while in the crlinder it is one of bursting, or (Continued on page 519)

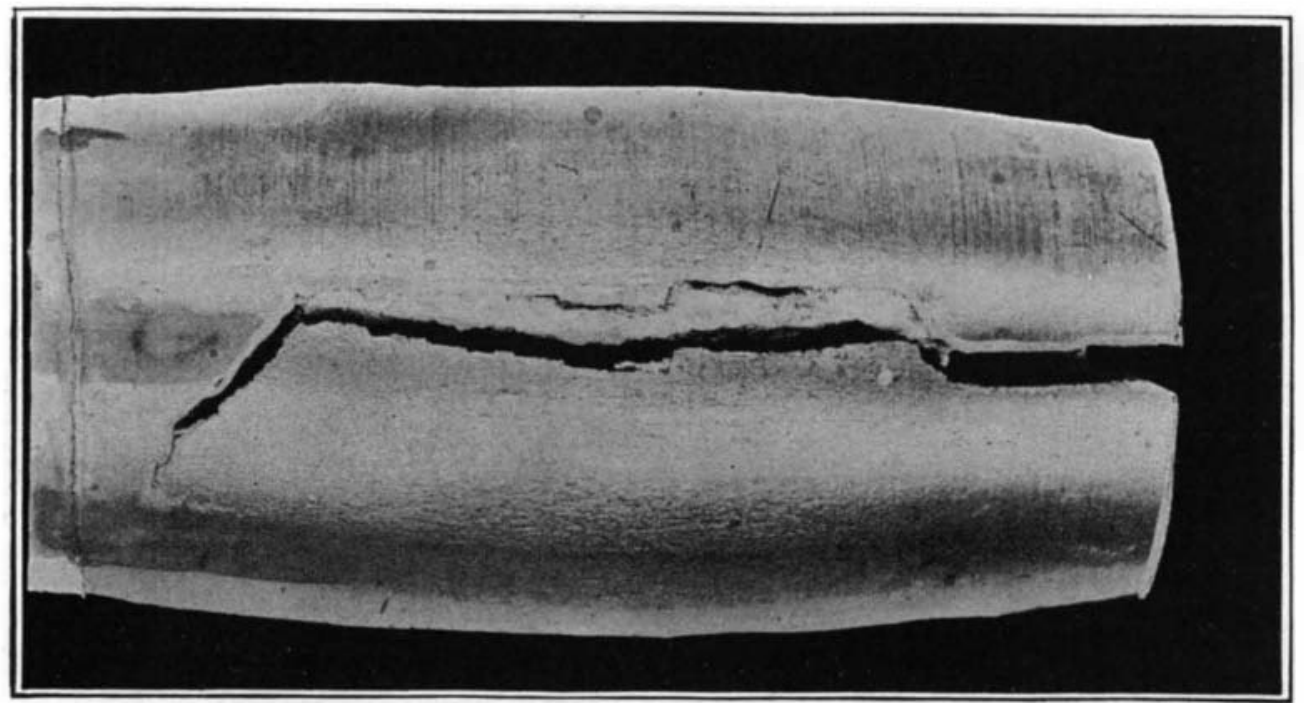

Outside of a cylinder stretched from 5 to 1.375 inch before rupture. $-A$ cross-section of this cylinder is shown in the upper illustration

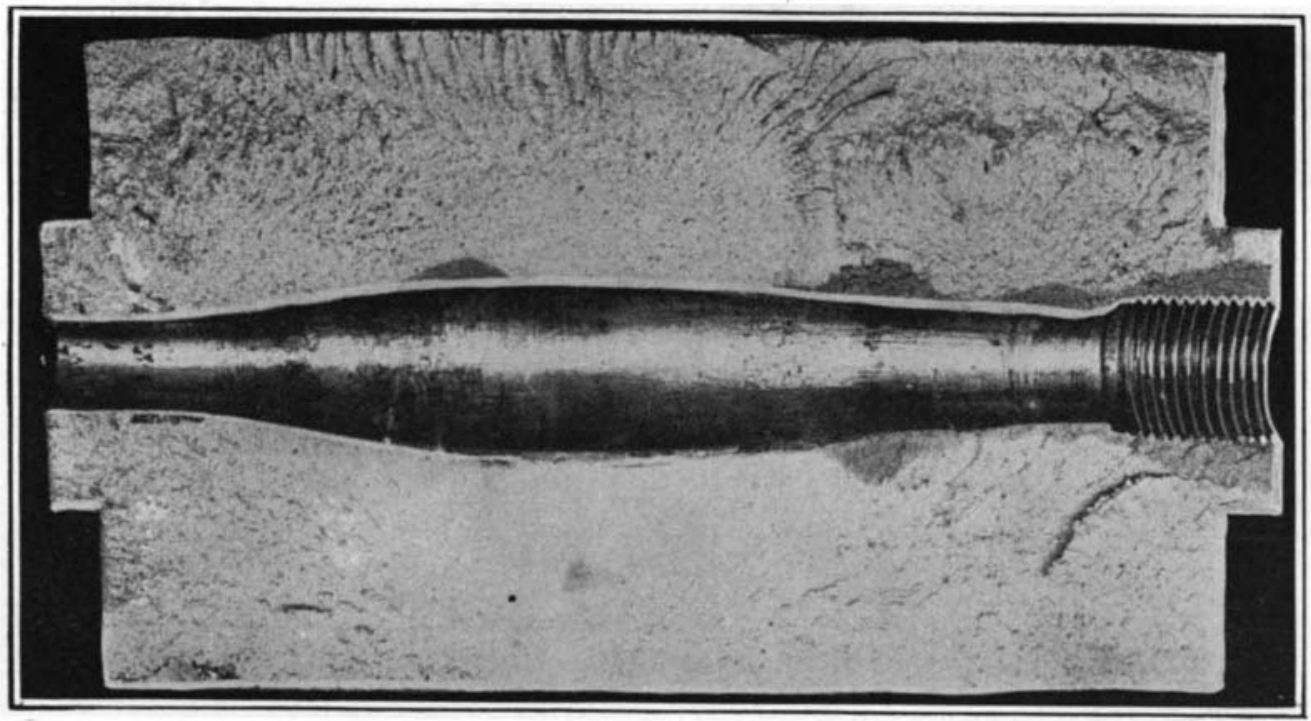

One of the halves of a steel cylinder split by 450,000 pounds internal pressure

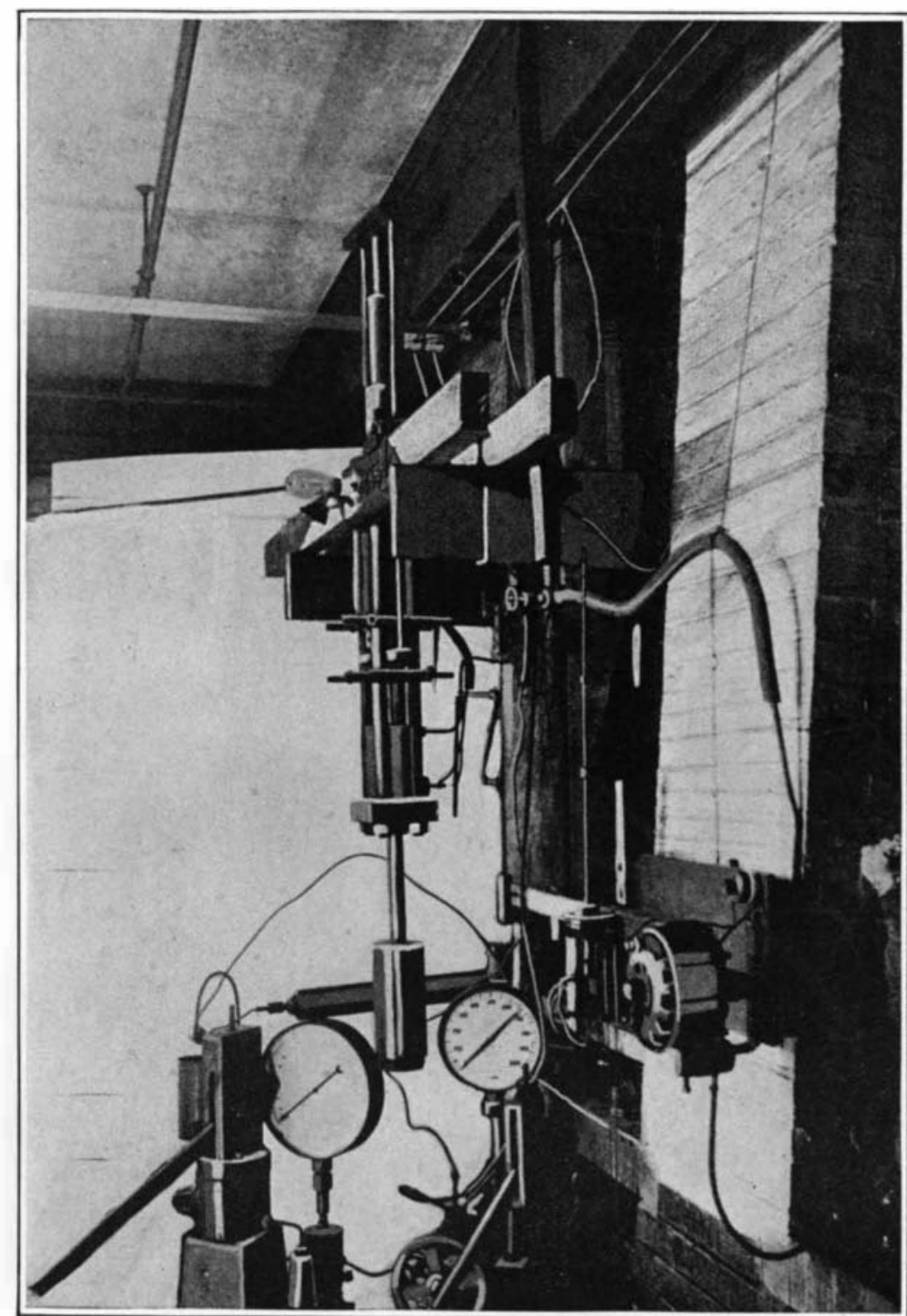

Apparatus used in the high-pressure experiments 


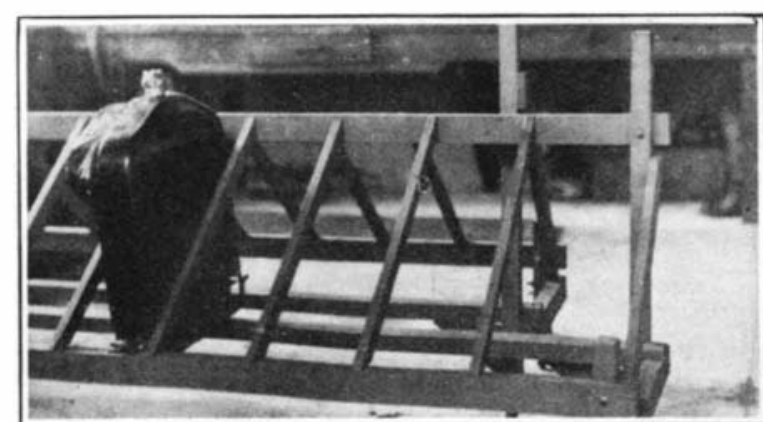

Handy rack for radiators before or after repair

The Armed and Armored Limousine of a Chinese Governor

N automobile fortress that is at the same time one $\mathbf{A}^{\mathrm{N}}$ automobile fortress that is at the same time one just been delivered to his excellency Tsan Tso-Lin, the Governor General of Manchuria. The machine, which in appearance and fact is the last word in luxurious transportation, is also an armored car, bullet and bomb proof and prepared either for offense or defense. It is likely to be a model for similar cars for other nervous rulers now that news of its construction is no longer a secret.

When General Tsan appears in the streets of Mukden or other Manchurian cities he will apparently be traveling simply in an amazingly luxurious limousine. The car has disk wheels, special headlights and is of a deep $\tan$ color with mahogans top and trimminaInside, the Inside, the fittings and finish are fully worthy of the offcial position of its owner. To conform to the colors of Chinese royalty the cushions, seat backs and arms are upholstered in purple and gold mohair. The panels lining the body are entirely of inla:d mahogany, and there are vanity cases of the same material on and there are vanity cases of the same material on tonneau are of silver and cloissonné. Perhaps the tonneau are of silver and cloissonné. Perhaps the most beautiful part of the interior decoration is the
flowered marquetry inlaid in the door panels. In each of these panels more than 20 different kinds of wood are used.

This is the car as it appears to the eye. But if an attempt is made by some assassin to end General Tsan's (Continued on page 520)

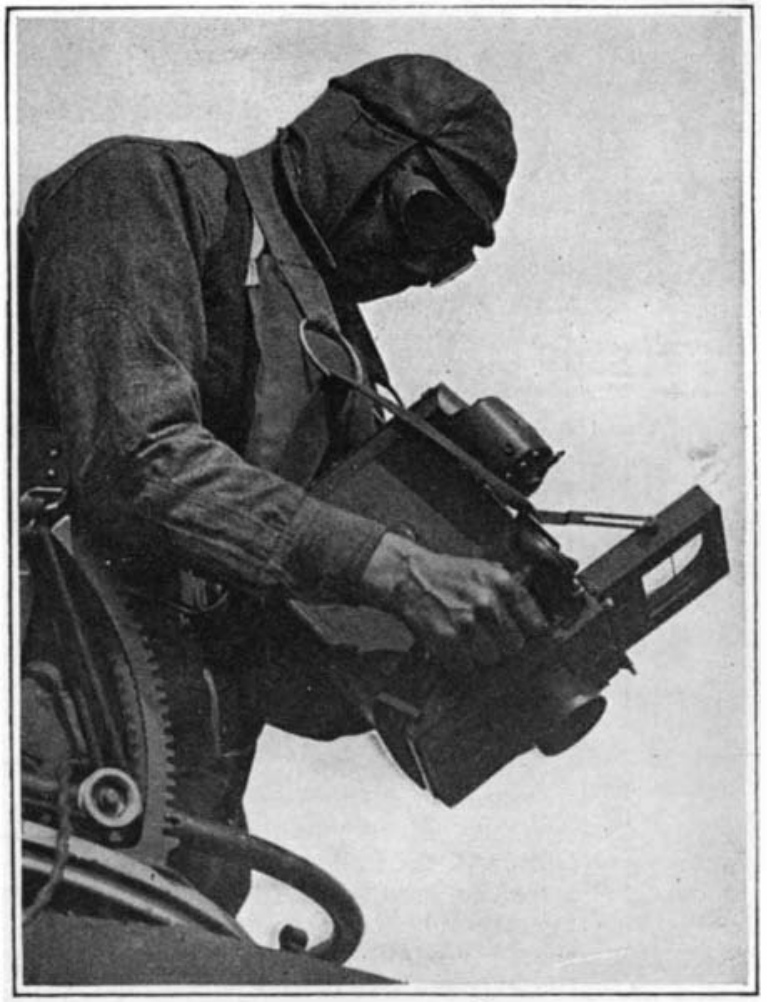

Electrically-driven motion picture camera that does away with the usual cumbersome tripod

\section{Garage Conveniences}

THERE is hardly any limit to the scope afforded by the garage for the exercise of mechanical ingenuity. Not alone are all sorts of complex problems met in the renovation and the up-keep of the cars, but met in the renovation and the up-keep of the cars, but the garage fixtures themselves offer great opportunity for the clever mechanic to put his talents in play. And the establishment equipped to do the ordinary and the extraordinary garage jobs with a minimum of time and effort is the one that will capture the business in the long run.

Two interesting wrinkles from a California garage are illustrated on this page. We have all seen radiators knocking around a shop of this sort waiting their turn to be soldered up or remounted, after being repaired, on the cars from which they came. There doesn't seem to be any logical place to put these; stand them against the wall, lay them on the floor, even place them aboard their cars, and they are in the wrong place. aboard their cars, and they are in the wrong place. has built a wooden rack for them; and it is at once clear that in this rack a radiator whether it has had the plumber's attention or not, is exactly in the spot where it is wanted.

Another garage nuisance-none the less annoying be-

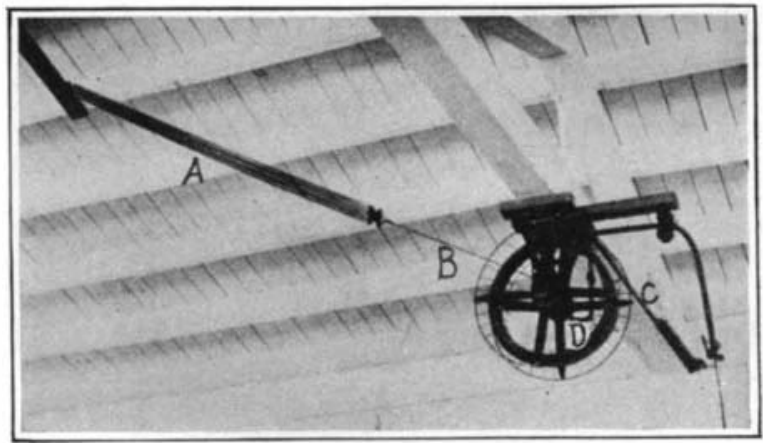

An overhead reel for the garage air-hose

Using X-Rays to Determine Proper Fit of Shoes

CERTAIN manufacturers endeavor to prove the merits of their shoes by showing photographs of the bones of the feet first in the ordinary shoe' and then in their specially-shaped shoe. Of course, such pictures are interesting, but they fail to leave a permanent impression in most instances; so that when any of us happen in the shoe store for a new pair of shoes, we are guided by the appear ance of the shoes rathe than by orthopedic considerations. Hence, after al said advertising and warnings, we continue to buy shoes that jam and twist and deform thie small bones of the feet.

Some time ago X-ray machines of a special design were introduced in shoe stores both here and abroad for the purpose of determining when shoes fit and when they do not. One of these X-ray machines appears in the accompanying illustration. The shoe customer, wearing a given pair of shoes, stands on the platform of the apparatus and by looking through the long

limousine that can be instantly converted into a traveling fort

cause so necessary-is the air hose. You may run over this, where it stretches its snaky length across the garage entrance as it extends from the pump to the wheel of a waiting car, dozens of times without damage to your own tires or to the hose; you may then run over it once more and damage either or both. You may also trip over it with more or less disastrous results. The garage in which our pictures are taken overomes all this by putting the air hose overhead, slinging it over a reel that is placed at a strategic point to give it the proper degree of easy mobility. The utility of both these simple but seldom-thought-of devices is evident at a glance, and the second one might even be installed with profit in the single-car private garage, where some other agent than elbow grease is employed in the pumping job.

\section{A Tripod-less Motion Picture Camera for} Aerial Work

THE main thing in making motion pictures is to keep turning the crank at an even speed, two turns per second, no matter what happens. Under normal conditions this is not so difficult to do, but when making aerial views with a motion picture camera the most intrepid cameraman is apt to become irregular on his turns with poor films as a result What is more, the vibration of the airplane engine is transmitted through vibration of the airplane engine is transmitted through

Realizing these difficulties in the way of aerial motion pictures, Frank Morris of New York has developed an electrically-driven motion picture camera which is shown in the accompanying illustration. The camera shown here appears to be a French Débrie, somewhat modified and equipped with a 1/20-horsepower electric motor operating on an eight-volt storage power electric motor operating on an eight-volt storage on top of the camera, while a pair of handles is used to hold the camera steady. Furthermore, the cameraman wears a pneumatic chest pad against which he holds the camera, so as to make for greater stendiness while absorbing all vibration.

Aside from aerial photography the electrically-driven camera may be used in filming automobile and horse races, athletics, sports, and so on, where the lens must be trained on a rapidly moving object. hood at the top, views the X-ray image of the shoes and feet. The positions of the various bones can be instantly seen. What is more, only a low power X-ray tube is used, and ample lead screening is employed to protect the customer and the shoe salesman from injury.

It is interesting to note the ever-widening field of X-rays. Today X-rays are being used in numerous industries for inspecting materials and goods to detect hidden flaws and to discover causes of trouble apparatus without complete dismantling. For customs inspection purposes X-rays have a very definite application, which, as yet, has been hardly touched.

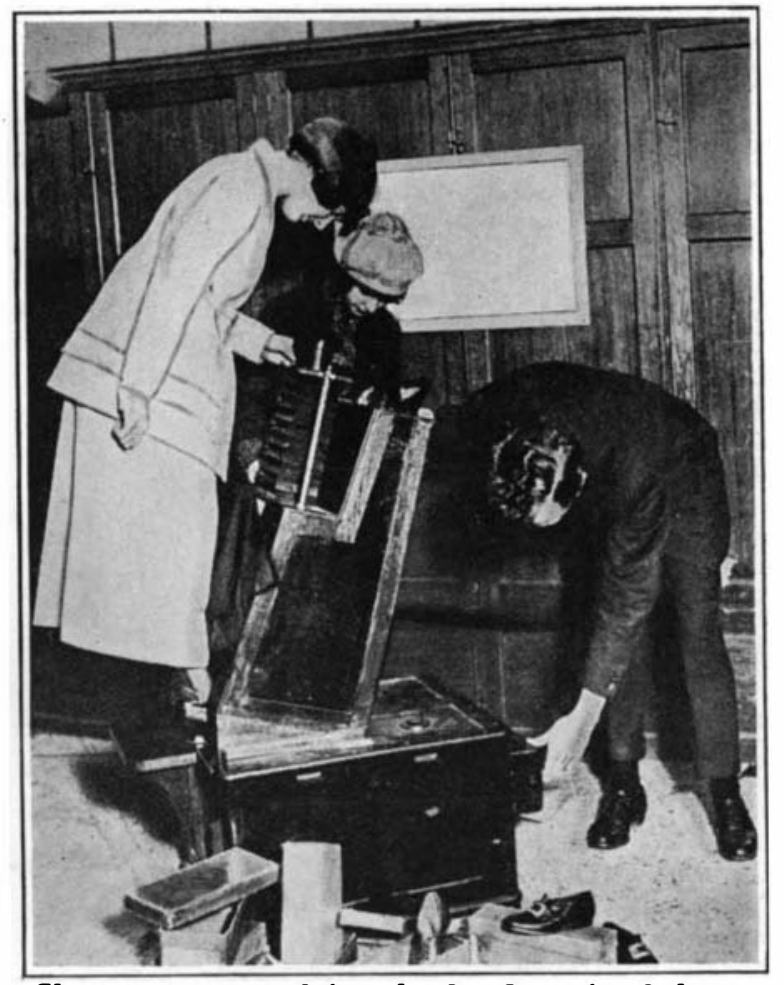
by means of a special X-ray apparatus
Shoe customer studying the fit of a pair of shoes 
tempt to enforce this. In many more the nuisance has got to such a point that it has been necessary to institute recognized public parking plots. Those who attend the ball games in New York know perhaps the most extensive of these-we have seen half a mile of the Speedway curb banked solid with cars, backed in as close together as the prohibition against two bodies occupying simultaneously the same space would permit. But in the more crowded sections of New York and other cities there are no extensive curb areas available for parking in this fashion. It is therefore necessary to utilize to the utmost whatever of open space there may be at hand. Our final picture shows how this is done in one instance. In a wide and little used street chalk lines are carefully laid down, so that two double ranks of cars may be parked without interfering with the entrance or exit lines. This is economy of space carried to the last degree.

Racing with Model Yachts

(Continued from page 511)

In the Regatta races boats sail according to class; but in the point races class is not taken into account Prizes are given to the winners for the season.

The Prospect Park Model Yacht Club at present is made up of former members of the Brooklyn Model Yacht Club and the Yankee Model Yacht Club, who agreed to join into one organization for at least six months. This plan has worked out very well and will no doubt result in a permanent organization probably under the present name.

The enthusiasm of the yacht races is not confined to the older members of the club, the younger members being fully as expert yachtsmen. On the large lake at Prospect Park, the triangular course is five-eighths of a mile, and on the windward and leeward course the yachts sail a half-mile by covering their course twice. Some excellent scores have been twice. Some excellent scores have been
made over this course. Thus the schooner "Fairwind" covered the triangular course in 12 minutes 55 seconds. The "Hilma" covered the same course in elapsed time 13 minutes, or 15 minutes 17 seconds by corrected time.

Quite a lively sight is the start of one of these races when more than half-adozen of the yachts are jockeying for the best position to cross the line, while on the shore opposite the stake stands the timer with his watch and recording tablets, keeping accurate account of the time each one crosses.

Collisions happen frequently, but they are not usually serious, the damage being easily remedied. In a heavy wind the yachts heel over to an alarming degree, but thanks to their deep lead keels, always right themselves. So great is the speed of the large yachts that the owners frequently have to put in some hard rowing to keep up with the diminutive but fast-moving craft.

\section{Concerning Ice}

(Continued from page 512)

tension. The problem of the strength of the piston did not prove of difficulty, for it was found that the compression supported by a piece of glass-hard steel held rigidly is surprisingly large. Several grades of steel were found which would grades of steel were found which would
support a compression of 600,000 pounds and one grade stood up under as much as 750,000 pounds per square inch.

No theory of the strength of a cylinder was of much value for very high pressures. It is of no use to make indefinitely thick walls, nor indeed to make them more than a certain thickness; for the inside layers support most of the pressure in any event. The outer layers of a very thick cylinder do not take up the stress from the inner layers. Dr. Bridgman concluded that the best way to make a cylinder support a high pressure was first much higher pressure than it was intended

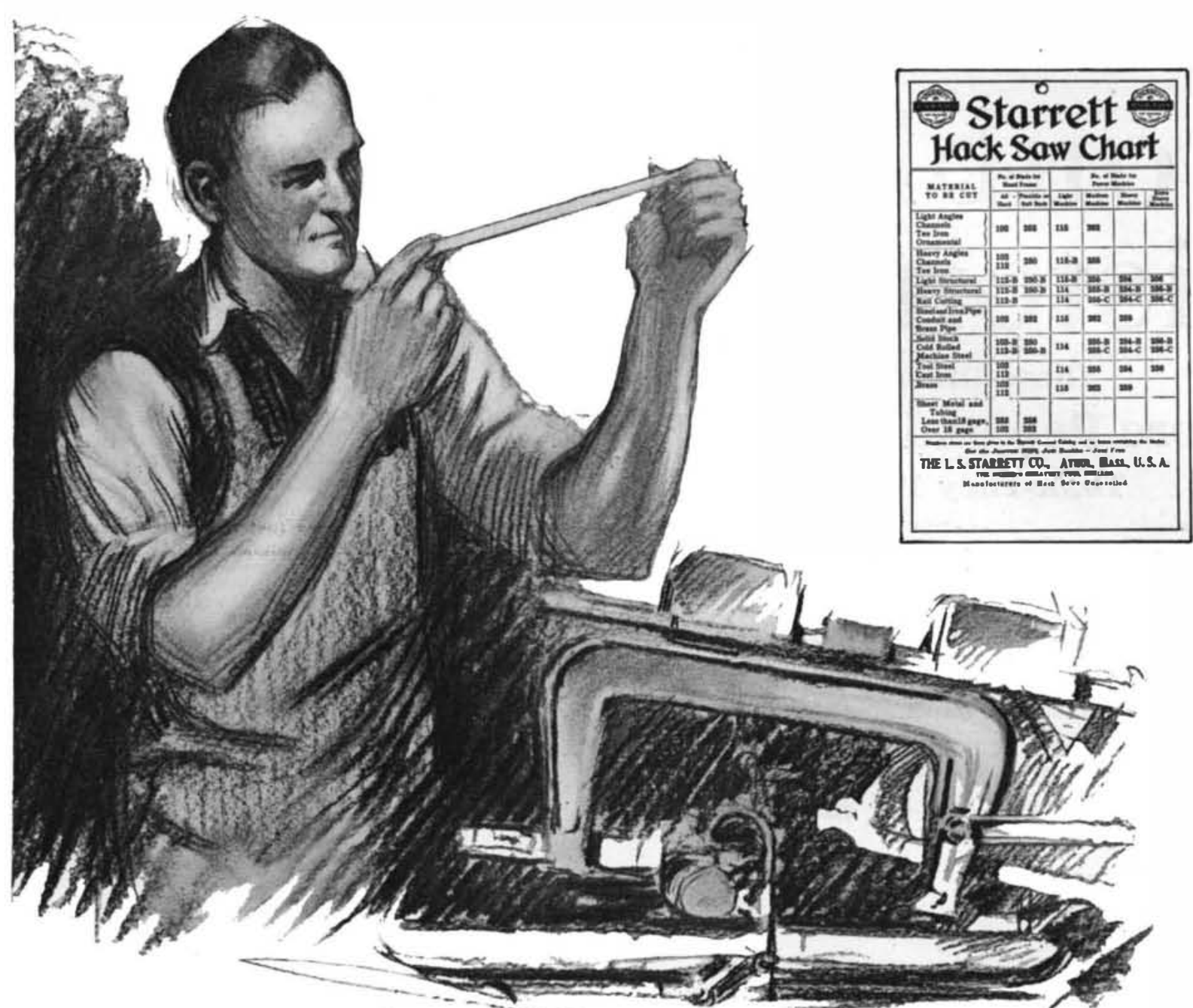

\section{The gage of a blade directly affects its cutting speed.}

Take two hacksaws, both suited to cutting some particular kind or shape of metal but differing only in the matter of gage. The thinner of the two will cut the quicker.

The contact area of the larger blade-the square area of the saw in actual contact with the work-means more friction to be overcome, and after the first few cuts, more weight upon the saw becomes necessary.

The Starrett Hacksaw Chart indicates the most efficient type of blades to use on any given kind of work. Starrett Saws, used according to it, give the best results.

Send for Catalog No. 22 "B"

\section{THE L. S. STARRETT COMPANY}

The World's Greatest Toolmakers
Manufacturers of Hack Saws Unexcelled. ATHOL, MASS.

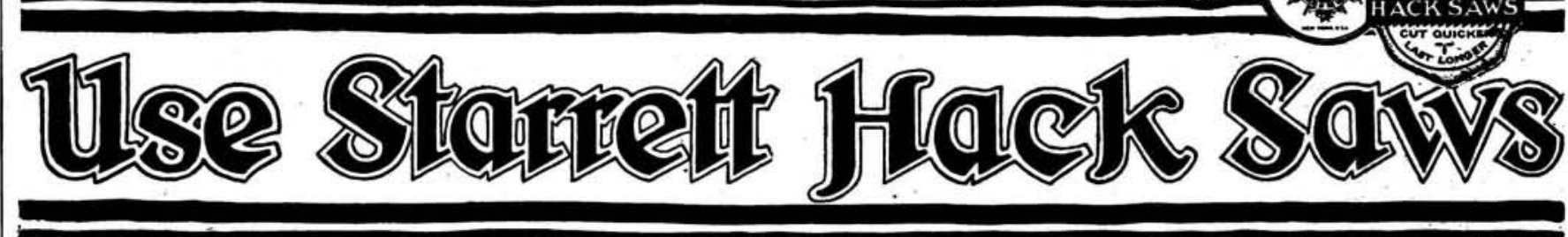

Attention to Details Essential to Efficiency

The necessity of increasing the weight as the saw is dulled must not be overlooked, and is a factor for Thich no absolute rule can be given. The most that can be said is, knowing approximately the time in which a cerimen of a certain kind and size of material, the weight should be. increased by increments of from 5 to 10 pounds as often as the time of three successive cuts is above the average. Remember that the weight on a heavy gage saw to the extra amount of dulled surface or contact area, than for a thinner gage saw, regardless of the difference in weights on the first cut with each. In Hack Sawing, as in any other form of work, common sense, attention to detail and observation of manufacturers' instructions are great assets.

To sum up: The attainment of rea efficiency in cutting metals with eithe hand or power Hack Saws depends upon:

1. The selection of the proper make of saw

2. The selection of the proper saw of that make for the material that is to be cut.

3. The proper use of the saw selected. It is possible for any user of Hack
Saws, at the expense of time and money, to evolve for himself a system for selecting and using Hack Saws to the best advantage. It is likely there are many machinists whose experience is sufficiently wide to warrant their making their own selection of saws and establishing their own code of usage. To this class of men, this book will have been but little more than a confirmation of facts they already know. To the man who has not had the advantage of such wide experience, it is hoped that this book will prove of value in his search for the means of more efficient work and methods.-From "He. effient and Their Use" published by The L.S. Starrett Co., for free distribution. 


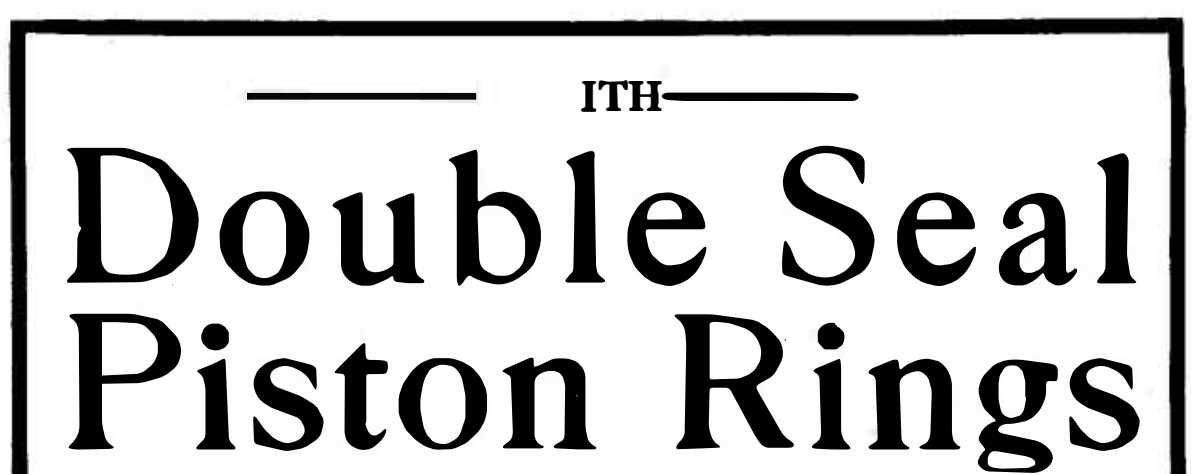

These Old Trucks Have

More Pep and Pulling Power

Than They Did When New

READ THIS LETTER

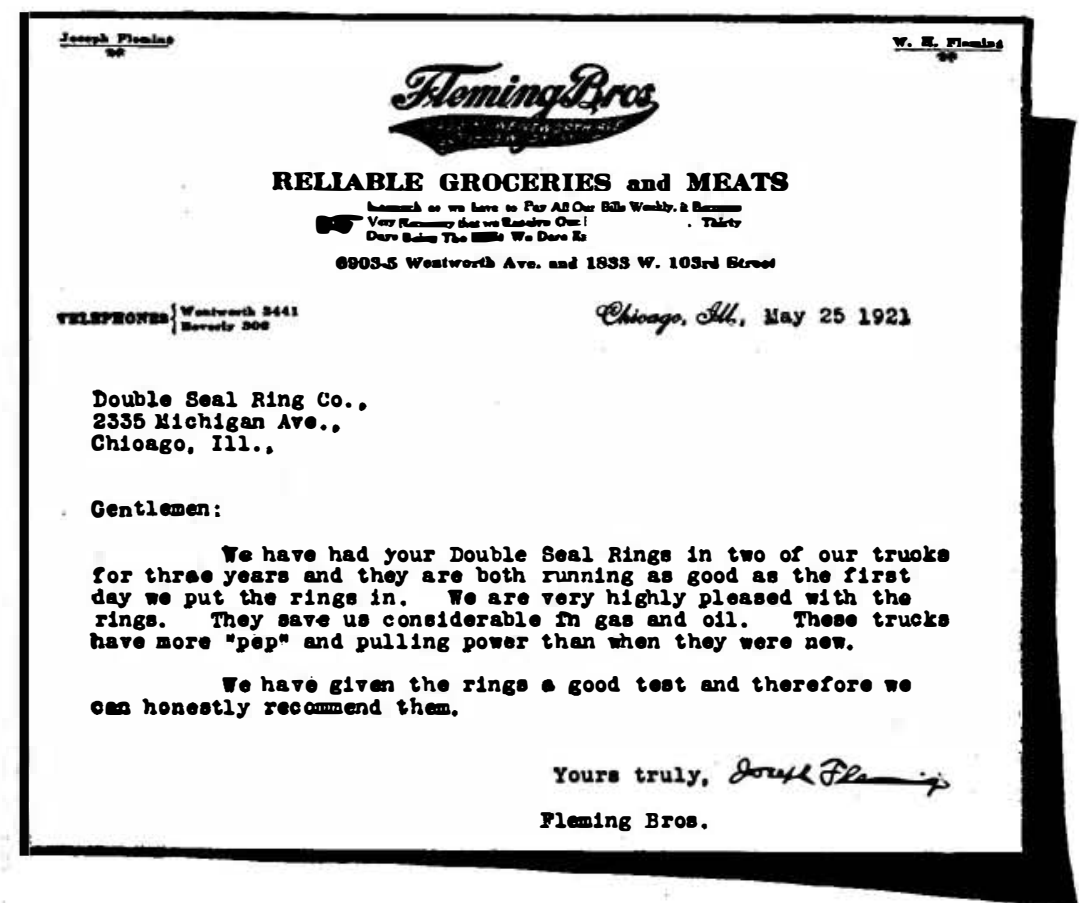

Double Seal Ring Company

General Sales Office, 2335 Michigan Avenue, Chicago, Illinois Brenches in 30 Large Cities

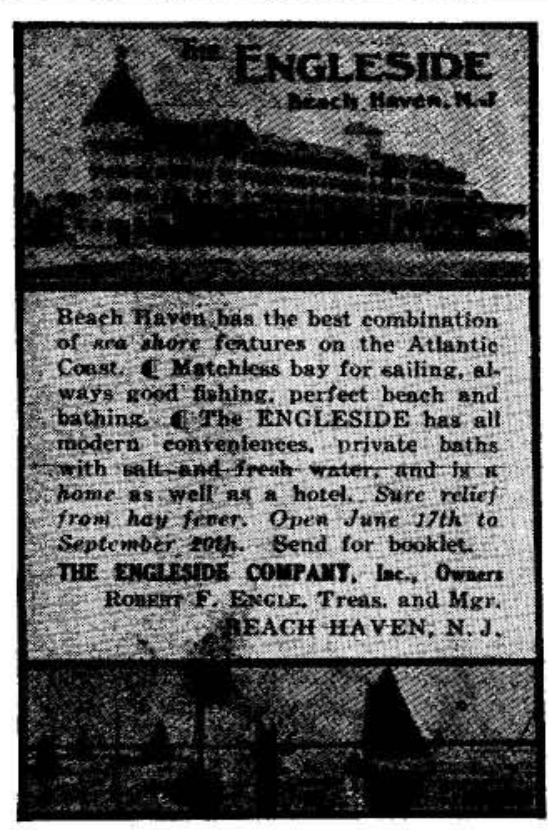

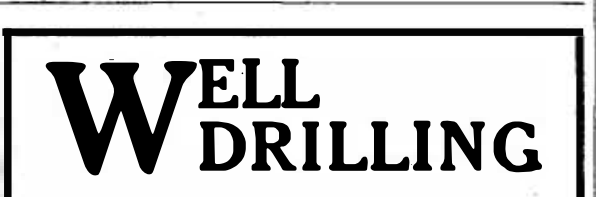

A Paying Business

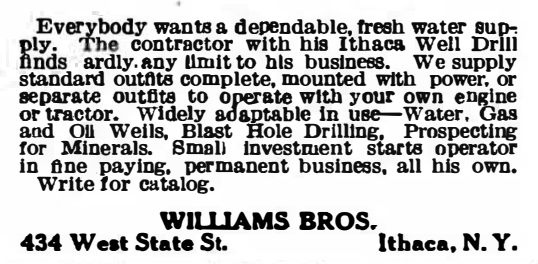

MAXIM SILENCERS For Rifles. Tarret Pittolo, Exhausto. Air Com-
prewores, Farm Enginea, Motor Boatz. Large prearorst. Fam Enginets. Motor Boats. Largo Manefactorins rights mailable. Write for information MAXIM SILENCER COMPANY
Hartford, Conn.
Order Your Scientific and Technical Books Now They are diffecult to obtain a nd prices are constantly Increasilig. We will quote present price on any book
of this nature and the price will hold unless the publisher shouid increase his price in the interim.

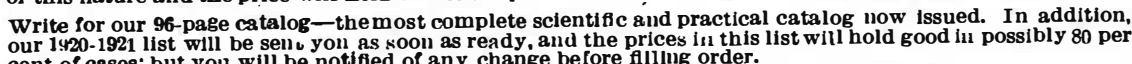

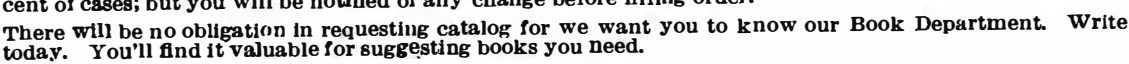
SCIENTIFIC AMERICAN PUBLISHING CO., Room 676. Woolworth Bldg., New York City to maintain in practice. It was found that a cylinder treated in this way is in a state of internal strain, exactly as is a gun which has had hoops shrunk on
it from the outside. As a result of the experiments a cylinder half an inch in diameter was stretched to 1.2 inch in diameter before breaking; and the break, when it came, started on the outside. when it came, started on the outside.
In the preliminary work on steel cylin ders many cylinders were broken. This gave opportunity for interesting observations on the manner of rupture at high pressures, and two facts not to be expected from ordinary theory were noted. The same specimen of steel which stretched more than its diameter under pressure, if tested for strength in the ordinary way, would have broken when the strain became about 30 per cent, whereas the strain here was about 140 per cent before rupture took place. In all cylinders tested the break started at the outside, where the stress and strain were both least. There is reason to believe, however, that very brittle substances like glass would break on the inside, as predicted by the ordinary theory. The determining factor here, according to the experiments, is the plasticity of the substance.

Another important factor was the devising of some means of accurately meas uring the pressures. None of the ordinary pressure gages were found to be of the slightest service at these high pressures. Again, strange to say, the very simplest method that can be conceived proved to be the best. It consists in inserting a steel piston through a hole in the wall of the cylinder and measuring the force necessary to prevent it from being blown out by the pressure within. The minute the preliminaries were con cluded and the actual experiments with water begun, it was found that the high pressures made the water disobey all the ordinary rules. The application of ordinary pressure to ice causes it to melt. But when ice is subjected to pressure at temperatures lower than ten below, Fahren heit, it is no longer possible to make it melt, but instead it changes in form, passing over into another kind of ice more dense than water, instead of less dense like ordinary ice.

The pressure required to produce this second kind of ice is about 33,000 pounds per square inch. These two forms of ice are comparable to the two forms of car bon-graphite and diamond; with this difference: the new kind of ice changes to ordinary ice the moment the pressure on it is relieved, just as ordinary ice changes to water on the provision of suf ficient heat. Old principles are borne out, however, and old reasoning supported, by the fact that when the ice is of less density than water, the freezing point is lowered by the application of pressure; while if the ice is of the denser-than-water va riety, pressure raises the freezing point

The Armed and Armored Limo sine of a Chinese Governor (Continued from page 513)

term of office with a bullet, as is so frequently the fate of Chinese officials, the car can be transformed in a twinkling Down from inside the roof come stee shutters covering all the windows and reaching to the steel plates built inside the walls of the car. Concealed loopholes open on each side and in the rear, and six automatics or rifles can come into action. Another steel shutter rises out of the partition between the tonneau and the driver's seat, closing off danger from the front. A Colt machine gun appears from under the driver's seat and is fast ened on to a special bracket built in at the right hand side of the cowling. The luxurious car is thus turned into a fortress.

As an additional measure of safety in dangerous times, there are fastened to each side of the car three swivels. Belts are provided that fasten into these with
LEGAL NOTICES

\section{PAT E N T S}

IF YOU HAVE AN INVENTION 1 which you wish to patent you can write fully and freely to Munn \& Co. for advice in regard to the best way of obtaining protection. Please send sketches or a model of your invention and a description of the device, explaining its operation.

All communications are strictly confidential. Our vast practice, extending over a period of seventy years, enables us in many cases to advise in regard to patentability without any expense to the client. Our HandBook on Patents is sent free on request. This explains our methods, terms, etc., in regard to Patents,
Trade Marks, Foreign Patents, etc.

SCIENTIFIC AMERICAN Contenino Patent Office Notes, Decisiona of interest to inventori-and

MUNN \& CO., goingitents Woolworth Building.
Tower Buildiag.
CHICW YORK Scientific America Buildias, WASHINGTON. D. C. Hobar Baildizs,

Annual Subscription Rates

Annual Subscription Rates
Scientific American Publications Scientific American (established 1845) one

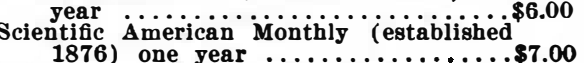
18ge prepaid in United $\ldots \ldots \ldots \ldots \ldots \ldots$ states and posses-
sions, Mexico, Cuba and Panams Foreign Postage

Scientific American $\$ 1.50$ per year additional
cientific American Monthly $72 \mathrm{e}$ per year additional. Canadian Postage Scientifc American 75c per year additional.
Scientific American Monthly $36 \mathrm{c}$ per year addiThe combined subscription rates and rates to
foreign countries, including Canada, will be Remit by postal or express money order, bank
draft or check. AGENTS WANTED AGENTS, 860 to $\$ 200$ a week. Free samples. Gold
Sign Letters for Store and Office Windows. Anyone can do It. Big demand. Liberal offer 10 general agents.
Metallic Lettur Co., $431 \mathrm{X}$ N. Clark St., Chicago. BUSINESS OPPORTUNITY

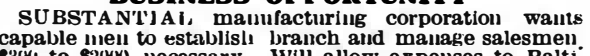

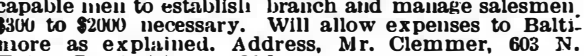
Eutiw St.. Baltimore. $M \mathrm{~d}$.
BUSINESS OPPORTUNITY YOU CAN have a business professlon of your own and
earn big income th service fees. A ntew system of foot correction; readily learned by anyone at home in a few
weeks. Easy terms for tralling ; openings every where
with all the trade you cann attend to. No capital rewith all the trade you can attend to. No capital re-
quired or goods to buy, ino agency or soliciting. Audress
Stephenson Laboratories 23 Back Bay, Bostol, Mass. CORPORATION SERVICE GREAT CARE should be ex ercised at the inception
o $\mathrm{a}$ new enterprise to insure its fnanicial success. We render a spectalized, complete service. If you contem-
plate incorporation or reorgauization let us solve your plate hicorporation or reorgauization let us solve your
problen. Inquiries solicited. Industrial Engineering
Corporation, Engineering Building. 114 Liberty Street. Now York.
FOR SALE

STEEL Tower and Tank Capacity about 1.800 gal-
lous. In good condition. Can be seen ou premises.
A. J Murphy, Laurel House, Lakewood, N, J.

FOREIGN STAMPS
65 DIFFERENT STAMPS, including China, Japan,
French Colonies, etc. given to a pplicauts for our high grade approval selectious. Send references aud 2e stamp
to the EDGEWOOD STAMP CO., Dept. $G$, Milford, GELP WANTED
SPLENDID clerical work opportunity.
whole time.
No canvassing, ood noney. Chautauqua \begin{tabular}{l} 
SPLENDID clerical work opportunity. $\begin{array}{c}\text { Spare or } \\
\text { whole time. No canvassing. good nloney. Chautauqua }\end{array}$ \\
Business Bullders, Jamestown, N. Y. \\
\hline
\end{tabular}

INCURPORATION IN ARIZONA COM PLETED in 1 day. Any capitalization. least cost.
greatest advantages. Transact business anywhere.
Laws, By-Laws and forms free. Stoddard Incorporat-
ing Co., 8-4. Phoenix, Ariz. WANTED

MANUFACTURING rights on metal articles. Also
metal stampings and model work on contract. We metal stampings and model work on contract. We
are ideally located and equiped to develop patents.
Meyers Company, Box 263 , Bedford, Indiana. Stop Oil Pumping Increase Mileage Decrease Oil, Fuel and Water Co

ZELNICKER EVER-TYTE PISTON RINGS Send for Free Evidence Booklets ST. LOUIS

Experimental and Model Work

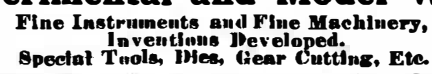
HENRY ZUHR, 489-93 Broome St., New York City 


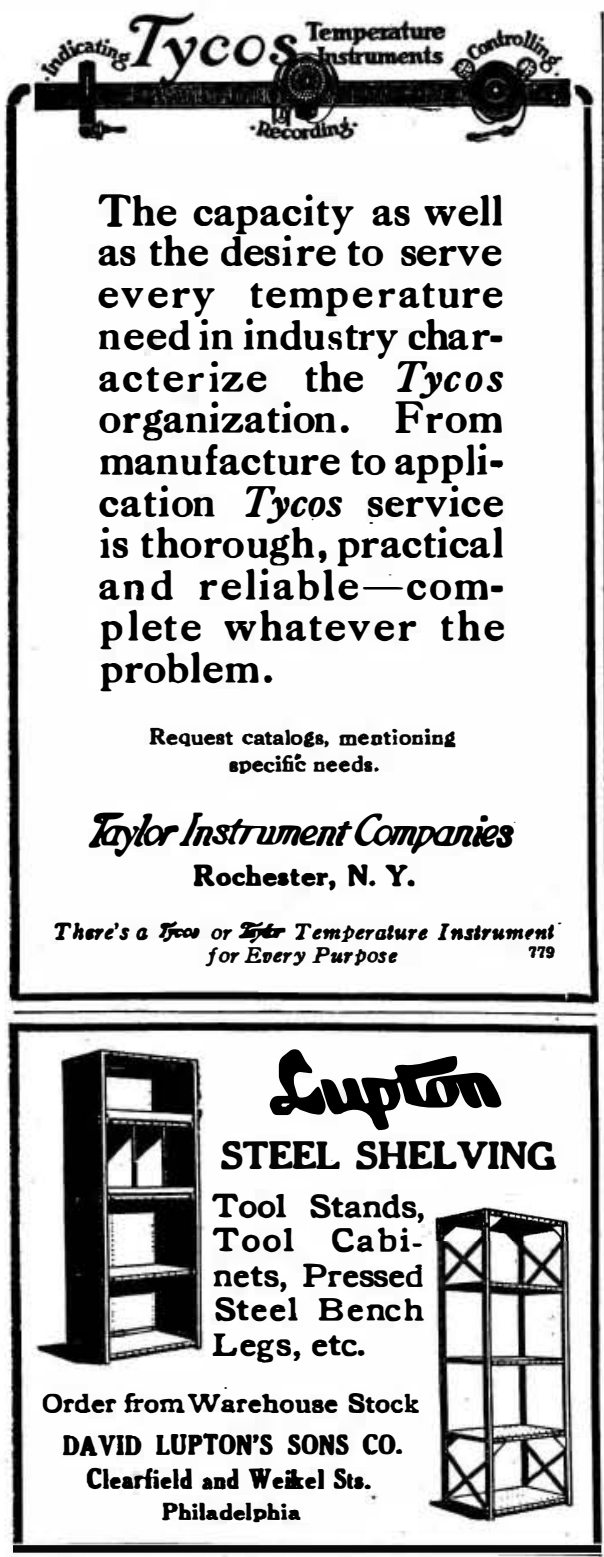

For Gunsmiths, Tool Makers, Experimental \& Repair Work, etc.
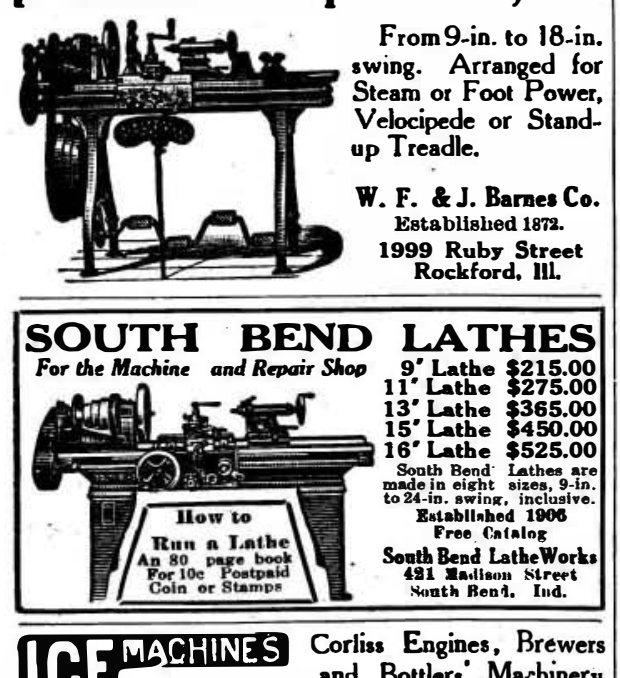
GL and Bottlers' Machinery 989 Clinton The VILTER MFG. CO.

\section{ASBESTOS}

We are miners and shippers of Crude Asbestos in an quantity. We produce all grades at our world famous
BELL ASBESTOS MINES in Canada. We also carry fibres, spin yarns, weave cloths, and make all
Asbestos products.
For anything you want in Asbestos, turn to

KEASBEY \& MATTISON COMPANY AMPLER DEPT. S-1

aners of the word's largest Asbostos mines

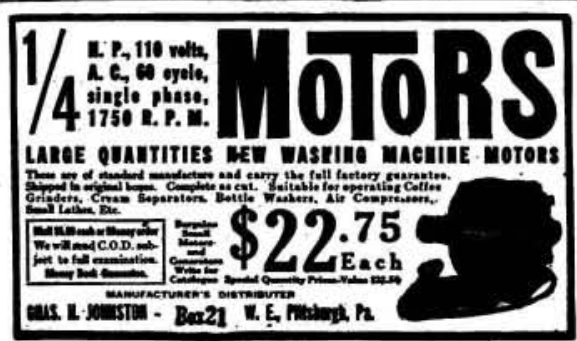

a snap hook so that soldiers may be strapped to the running board and have both hands free to use rifles. Handles have been attached to the steel roof of the car for their convenience. So if attacked the car can in a moment become a bullet proof steel bor, defended by a machine gun and six soldiers on the outside and by six more rifles from the side and

The Print and Label Law

(Continued from page 514)

ities, substantially as in the trade-mark law. Consequently a design to be placed on letter heads, cards, etc., as mere ornamentation and not being itself suggestive of any other article of manufacture, was enied registration; as was also a print designed to be used as a marker for a highway, though the same might be eligible for registration at the Copyright Office as "pictorial illustrations or works connected with the fine arts."

The word "designed" in this connection does not refer to the state of mind or intention of the author, but to the subjectmatter or quality of the print or label itself, and if that subject-matter does not suggest or in some manner identify the particular goods for which it is used, the work is not registrable in the Patent Office.

The Commissioner must determine for himself whether or not the work presented is registrable as a print or latel, and his decision, even though erroneous, cannot be reviewed by mandamus proceedings. But no nice application of rules will be made in the Patent Office to determine the degree of artistic quality displayed by the print or label; it will be registered as a print or label; it will be registered as a of a character which is commonly reof a character which is commonly re-
garded as the result of artistic or intel-
lectual effort, or which might properly be lectual effort, or which might properly be so regarded. Registration will only be refused if the article belongs to that class which is not intended for the production of artistic effect on the beholder and which does not in fact produce any; as where the label consists only of printed text with directions for use of the contents of the box or bottle to which it is applied.

On the basis of the foregoing principles the present rules of the Patent Office define a print as "an artistic and intellectual production designed to be used for an article of manufacture and in some fashion pertaining thereto, but not borne by it; such, for instance, as an advertiseby it ; such, for instance, as an advertise-
ment thereof"; and a label as "an artisment thereof"; and a label as "an artistic and intellectual production impressed or stamped directly upo slip or piece of paper or other material to be attached in any manner to manufactured articles or to bottles, boxes, and packages containing them, to indicate the article of manufacture." No print or label can be registered ture." No print or label can be registered unless it properly belongs to an article of manufacture and is descriptive thereor and is as above defined; but no examin will be made as to its novelt

Protection of Life Against Fire (Continued from page 516)

closed stairs-fire-resisting enclosure with fire doors. (d) Interior stairs-not en closed. (e) Elevator. (f) Outside stairs -not enclosed. (g) Outside fire escape, stairway type. (h) Outside ladder. (i) Special forms of fire escapes, such as chutes, poles and ropes.

The horizontal exit is believed by most fire protectionists to be the best for the protection of life, especially where there are a large number of persons on one floor. The occupants, after passing through a fire door or across a bridge are in a protected area from which they may descend in safety without excessive haste. Adequate stairways must, how ever, be provided for moving the occupants to the ground level as soon as the have passed through the horizontal exit (Continued on page 523)

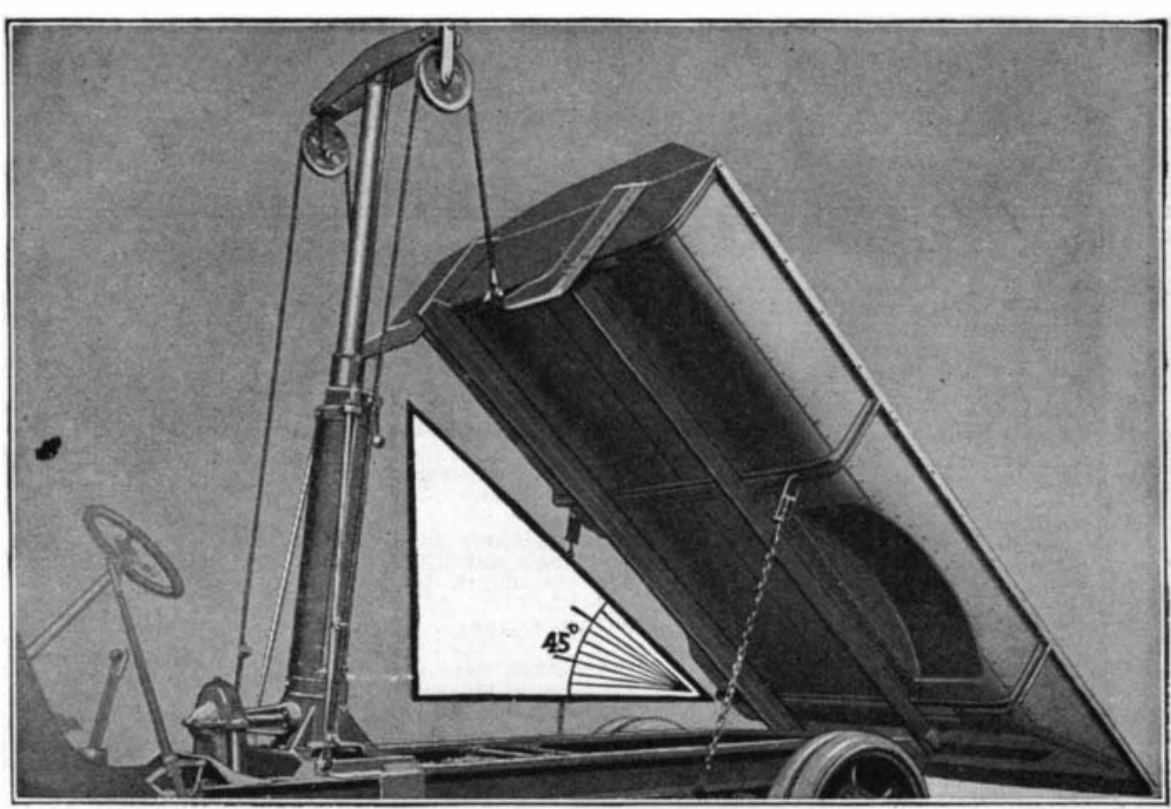

\section{Stopped, locked or lowered from any angle up to $45^{\circ}$}

There is no gradual "settling" of the raised truck body when it is held by a Van Dorn Hoist.

Stopping the hoist, firmly and positively locks it, and the body will be held rigidly in any angle until it is pulled down by the same power which raises it. Gravity plays no part in the operation. Work can be performed on the chassis under the raised body with perfect safety. Operation of the Van Dorn Mechanical Hoist is automatic in every detail. The hoist is started, stopped or lowered with the body at any angle up to $45^{\circ}-$ at which extreme dumping angle it automatically stops. The truck can be driving away with the body lowering - the hoist stopping and disengaging automatically when the body settles to its bed.

Complete bulletin descriptive of $V$ an Dorn Mechanical $V$ ertical and Horizontal Hoists, and Truck Bodies sent to any truck operator. $W$ rite

\section{THE VAN DORN IRON WORKS COMPANY \\ Cleveland}

Branches Long lsland City, N. Y., and Philadelphia Distributors in all other cities

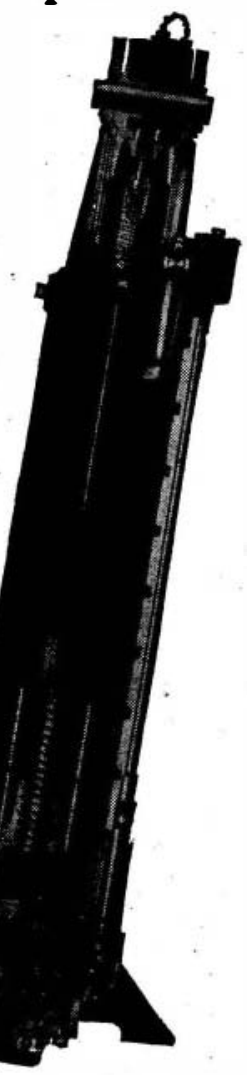

Cut away view of the $V$ an Dom Mechanical Hois principle of operation and the automatic lubricating showing the screw jack

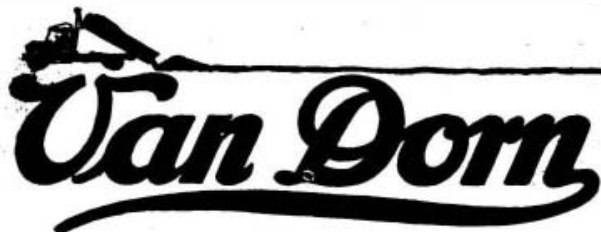

Mechanical Dump Truck Hoists. Bodies; Frames; Pressed Parts 